\title{
A Real-Time System for Monitoring Methane Level in Biogas Production
}

\author{
A Preliminary Study \\ Meta Yantidewi ${ }^{1}$, Utama Alan Deta ${ }^{2}$, and Nurita Apridiana Lestari ${ }^{3}$ \\ Department of Physics, Faculty of Mathematics and Natural Sciences \\ Universitas Negeri Surabaya \\ Surabaya 60231, Indonesia \\ ${ }^{1}$ metayantidewi@unesa.ac.id, ${ }^{2}$ utamadeta@unesa.ac.id, ${ }^{3}$ nuritalestari@ unesa.ac.id
}

\begin{abstract}
Methane is one of the flammable natural gas that can be found in biogas. Because of its flammable property, methane is mostly used as fuel. This research designed a monitoring system that can monitor the methane concentration level. The instrument system consisted of a methane gas sensor as a gas detector, microcontroller, and also $P C$ as the display system. The heating time of the methane gas sensor was about 25 seconds, whilst the measurement range was starting from 442 ppm until $9786 \mathrm{ppm}$. The results showed that the real-time system was capable to record around 19-20 data for 30 seconds.
\end{abstract}

Keywords-methane; instrument system; measurement results

\section{INTRODUCTION}

The demand for fossil fuels increases nowadays. A large number of vehicles and machines need fossil fuels to operate. About $88 \%$ of energy demand is fulfilled by fossil fuels [1]. Unfortunately, this increasing number is not followed by the fuel supply. At the same time, the pollution problems come to occur due to fossil fuels widespread consumption. To overcome this, scientists hold some researchers related to the alternative energies to meet global energy requirement in a sustainable way [2]. One of those alternative energies is biogas.

Biogas is a kind of renewable energy source (biofuel) produced by the decomposition of organic matter in the absence of oxygen. Biogas can be produced from agricultural waste, manure, household sewage, food waste, or green waste. The composition of biogas mostly depends on the type of decomposed material and subsequent slight differences in chemical compositions are capable enough to affect the results well [3]. Biogas mainly contains methane (50\%-70\%) and carbon dioxide (30\%-40\%) [4], although it also contains small quantities of hydrogen sulfide, nitrogen, water vapor, etc. [5]. The percentage of methane in biogas is varied depending on the process conditions and the type of organic matter fermented between $55 \%$ and $80 \%$ as Vintila and Dobre reported in Dobre [6]. Also, according to Sherman, the biogas quality is depended on the methane level in which the proportion of the constituent gas in the biogas, such as methane $\left(\mathrm{CH}_{4}\right)$ affects the combustion behavior of the gas fuel or biogas [7].

Departing from these facts, it is deemed necessary to design an instrumentation system for monitoring the concentration level of methane gas in which the data can be accessed in realtime. A real-time system is a high-speed data communication system. This system requires a data bank or database to accommodate all data received because the process of sending and receiving data takes place in a matter of seconds [8]. The database has been used since the beginning of computing era and has gone through a steady evolution, always changing, updating and developing to meet the world necessity [9].

\section{MATERIALS AND MeTHODS}

This study consisted of an instrumentation system which included methane (CH4) gas sensor, microcontroller, and the personal computer (PC) as the viewer data or display system in real-time. Overall, the block diagram of the instrument system is shown in Figure 1.

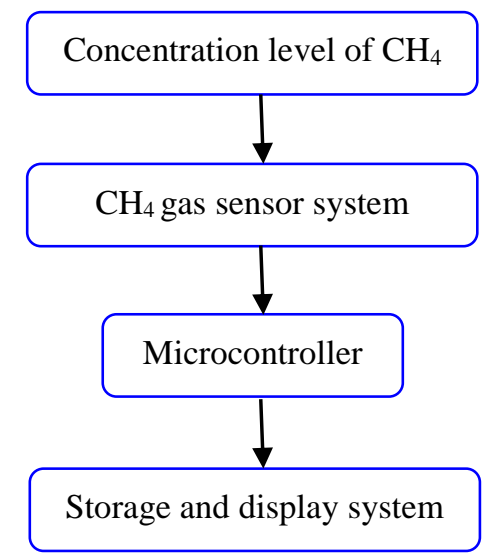

Fig 1. The block diagram of the instrument system

The picture above shows that the existing methane gas is detected by the methane gas sensor. The methane gas used in this study came from biogas, while the methane gas sensor used in the research was a metal oxide semiconductor gas sensor. Metal oxide semiconductor gas sensor was chosen because it is widely available in the market, has high sensitivity, easy to apply, has fast response, low cost, and has large number of possible application field $[10,11]$. As seen in the block diagram, the microcontroller received the data of methane gas concentration which were detected by the sensor. 
The microcontroller then sent them into the storage and display system in a serial way (serial communication). Serial communication is a data communication by sending one by one at a time unit. Data transmission on serial communication is undertook per bit. The data that had been received then being stored into a database and also be displayed on the PC. The advantage of data presentation using this system is to ease the further analysis.

\section{RESULTS AND DISCUSSIONS}

Before collecting data, the methane gas sensor was needed to be calibrated first. The calibration was held by comparing the output voltage of the sensor to gas measurement device Stargas Analyzer GDS8980TC. The calibration results are mentioned as follow:

\section{TABLE I. Methane Gas SENSOR CALIBRATiOn RESUlts}

\begin{tabular}{|l|l|}
\hline Measurement Range & $442-9786 \mathrm{ppm}$ \\
\hline Heating Time & 25 seconds \\
\hline
\end{tabular}

Like other gas sensors, the methane gas sensor also requires some heating time before it can be applied to detect and measure the gas concentration. The calibration result also shows that the minimum limit of methane concentration this sensor can detect is $442 \mathrm{ppm}$. On the contrary, the maximum limit of the measurement range is $9786 \mathrm{ppm}$.

As mentioned before, the methane gas sensor detected the concentration level of methane and sent it to the computer. The sending data of methane level was received by the computer serial communication and was treated by the software in a realtime way. The data were not only retrieved by the computer, but they were also stored and displayed by the computer. The figure below (Fig. 2) shows the methane level data on the personal computer (PC). This displaying data used Delphi as its software programming. Having a user-friendly design, large components, complex and realistic application, also fast compilation speed are the reasons for choosing this software [12].

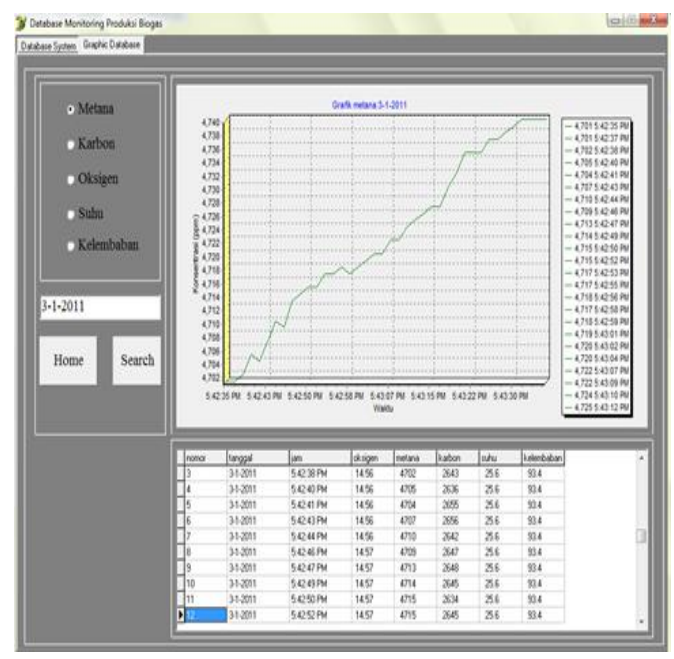

Fig 2. The display of methane level data on PC
The programming process so that the detected methane gas concentration is able to be displayed in real-time on the PC is explained by the following flow diagram (Fig. 3).

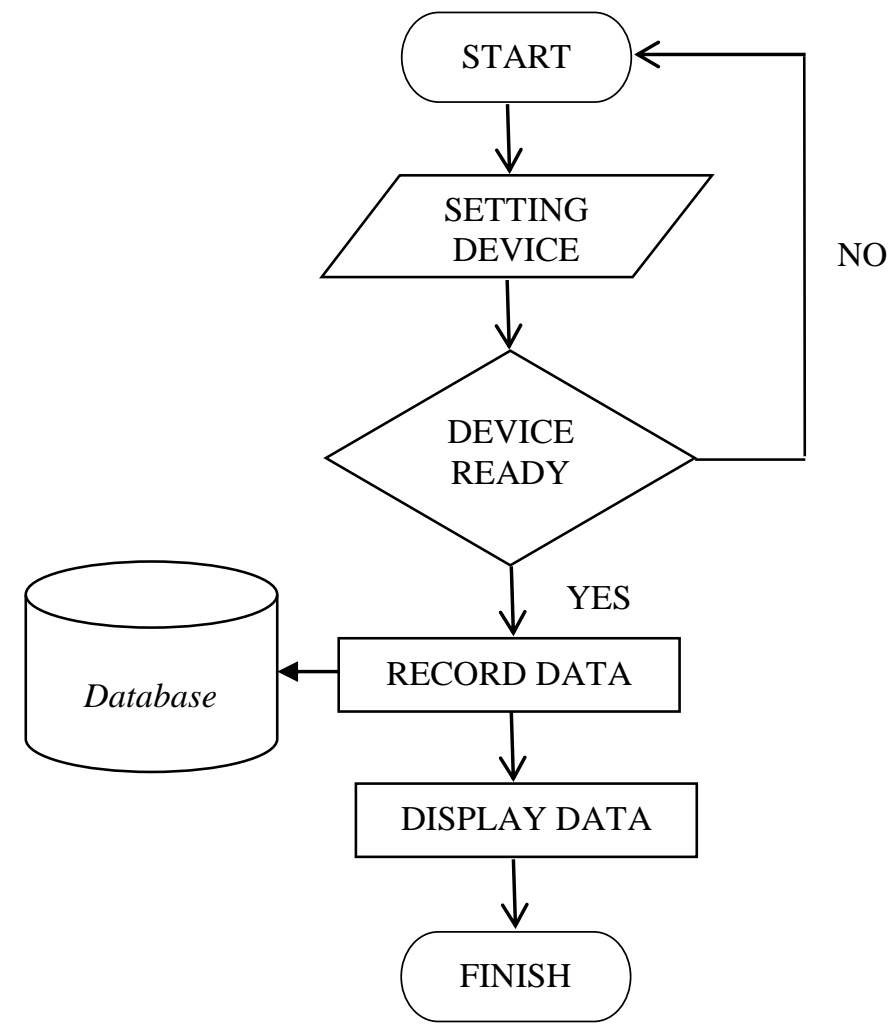

Fig 3. The flow diagram of the programming process in the real-time system for monitoring methane level

If the device or the instrument system is in the ready state, the device will transfer the information about methane level which detected by the gas sensor into the PC. Later, the PC will display and perform the data recording. Conversely, if the system is not in the ready condition then the monitoring system will return to its original or initial state (Fig. 3). From the flow diagram in Fig. 3, it can be seen that aside from displaying the methane level, the system also record and store the data of methane level into a database. A database is an organized collection of data or information, stored and accessed electronically for rapid search and retrieval by a computer [8]. Database is structured to facilitate the storage and retrieval of data by applying various data-processing operations.

In addition to displaying measurable levels of methane gas concentration, this instrument system also displays retrieval time as well as a graph of changes in methane gas concentration as shown in Fig. 4. The graph would change as the level of methane gas concentration was detected by the methane gas sensor. This was one of the advantages of the realtime system in which the visible data on PC was the real measurable data. 


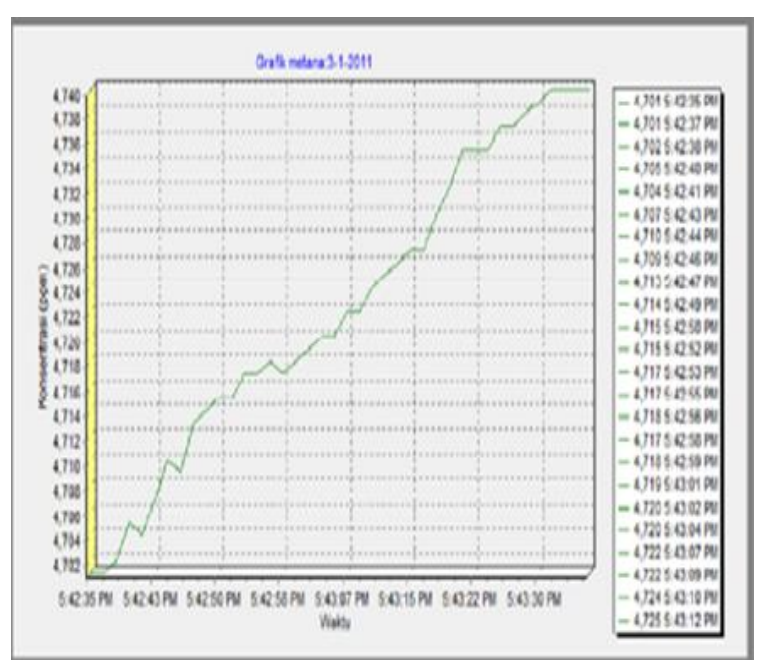

Fig. 4. Graphic display and data retrieval time of methane gas concentration on PC

TABLE II. MEASURED METhane GAS CONCENTRATION DATA FOR THE INITIAL 30 SECONDS

\begin{tabular}{|c|c|c|}
\hline Seconds & Time & ppm of $\mathbf{C H}_{\mathbf{4}}$ \\
\hline 33 & $5: 43: 07$ PM & 4722 \\
\hline 35 & $5: 43: 09$ PM & 4722 \\
\hline 36 & $5: 43: 10$ PM & 4724 \\
\hline 38 & $5: 43: 12$ PM & 4725 \\
\hline 39 & $5: 43: 13$ PM & 4726 \\
\hline 41 & $5: 43: 15$ PM & 4727 \\
\hline 42 & $5: 43: 16$ PM & 4727 \\
\hline 44 & $5: 43: 07$ PM & 4730 \\
\hline 45 & $5: 43: 09$ PM & 4732 \\
\hline 47 & $5: 43: 10$ PM & 4735 \\
\hline 48 & $5: 43: 12$ PM & 4735 \\
\hline 50 & $5: 43: 13$ PM & 4735 \\
\hline 51 & $5: 43: 15$ PM & 4737 \\
\hline 53 & $5: 43: 27$ PM & 4737 \\
\hline 54 & $5: 43: 28$ PM & 4738 \\
\hline 56 & $5: 43: 30$ PM & 4739 \\
\hline 57 & $5: 43: 31$ PM & 4740 \\
\hline 59 & $5: 43: 33$ PM & 4740 \\
\hline 60 & $5: 43: 34$ PM & 4740 \\
\hline
\end{tabular}

TABLE III. Measured Methane Gas Concentration Data ABove 30 SECONDS

\begin{tabular}{|c|c|c|}
\hline Seconds & Time & ppm of $\mathbf{C H}_{\mathbf{4}}$ \\
\hline 1 & $5: 42: 35$ PM & 4701 \\
\hline 3 & $5: 42: 37$ PM & 4701 \\
\hline 4 & $5: 42: 38$ PM & 4702 \\
\hline 6 & $5: 42: 40$ PM & 4705 \\
\hline 7 & $5: 42: 41$ PM & 4704 \\
\hline 9 & $5: 42: 43$ PM & 4707 \\
\hline 10 & $5: 42: 44$ PM & 4710 \\
\hline 12 & $5: 42: 46$ PM & 4709 \\
\hline 13 & $5: 42: 47$ PM & 4713 \\
\hline 15 & $5: 42: 49$ PM & 4714 \\
\hline 16 & $5: 42: 50$ PM & 4715 \\
\hline 18 & $5: 42: 52$ PM & 4715 \\
\hline 19 & $5: 42: 53$ PM & 4717 \\
\hline 21 & $5: 42: 55$ PM & 4717 \\
\hline 22 & $5: 42: 56$ PM & 4718 \\
\hline 24 & $5: 42: 58$ PM & 4717 \\
\hline 25 & $5: 42: 59$ PM & 4718 \\
\hline
\end{tabular}

\begin{tabular}{|c|c|c|}
\hline Seconds & Time & ppm of $\mathbf{C H}_{\mathbf{4}}$ \\
\hline 27 & $5: 43: 01 \mathrm{PM}$ & 4719 \\
\hline 28 & $5: 43: 02 \mathrm{PM}$ & 4720 \\
\hline 30 & $5: 43: 04 \mathrm{PM}$ & 4720 \\
\hline
\end{tabular}

From both tables above, it is seen that the system created is capable of recording data of approximately 19-20 data for 30 seconds. The above data also show that after 30 seconds, the methane concentration detected by the increase is more stable when compared to the methane gas concentration data in the first 30 seconds. The concentration of methane gas in the first 30 seconds remains unstable, as seen in the seventh $\left(7^{\text {th }}\right)$ and twelfth $\left(12^{\text {th }}\right)$ seconds of $4704 \mathrm{ppm}$ and $4709 \mathrm{ppm}$ respectively, whereas the methane gas concentrations at sixth $\left(6^{\text {th }}\right)$ and tenth $\left(10^{\text {th }}\right)$ seconds are $4705 \mathrm{ppm}$ and $4710 \mathrm{ppm}$. This corresponds to the sensor calibration results showing that this gas sensor has a heating time of approximately 30 seconds before it is able to use. In the other words, the data of the methane gas concentration that is really valid is the data at the thirty first $\left(31^{\text {st }}\right)$ and so on, until it reaches the maximum limit in detecting the presence of methane gas.

\section{CONCLUSIONS}

This real-time instrument system has the ability to record about 19-20 data in a range of time 30 seconds. The measured methane gas concentration data that is completely valid is the after 30 seconds according to the calibration result that the heating time of the sensor is 25 seconds.

Hopefully, through this study, a functional real-time system to monitor the level of methane gas in low-cost and easily obtainable biogas production can be achieved. Also, through the development of this real-time system, a future experimental research on biogas production can be carried out, considering the potential of biogas as an alternative energy.

\section{REFERENCES}

[1] P Weiland, "Biogas production: current state and perspectives," Appl. Microbiol. Biotechnol., vol. 85, pp. 849-860, 2010

[2] M Balat and H Balat, "Biogas as a renewable energy source - a review," Energy Sources, Part A: Recovery, Utilization, and Environmental Effect, vol. 31 (14), pp. 1280-1293, 2009.

[3] M Herout, J Malatak, L Kucera and T Dlabaja, "Biogas composition depending on the type of plant biomass used," Res. Agr. Eng., vol. 57 (4), pp. 137-143, 2011.

[4] The Effect of Temperature on the Rate of Digestion and Biogas Production using Cow Dung, Cow Pea, Cassava Peeling," International Journal of Scientific \& Engineering Research, vol. 6 (1), pp. 1255-1261, January 2015.

[5] N Oktarina, I Suryani and T M Akbar, "Pembuatan gasbio sederhana dari kotoran sapi," J. Nas. Ecopedon, vol. 4 (1), pp. 024-027, 2017.

[6] P Dobre, F Nicolae and F Matei, "Main factors affecting biogas production - an overview," Romanian Biotechnological Letters, Vol.19 (3), pp. 9283-9296, 2014.

[7] E Sherman, "Quantitative characterization of biogas quality," unpublished.

[8] M Yantidewi, "Pemantauan produksi biogas secara waktu nyata," unpublished.

[9] P F S Teixeira, L F Moura, S W S Lima, D Albiero, F A Gondim and A $\mathrm{R}$ de Alexandria, "Development of a low-cost data acquisition system for biodigester,” J. Bioenergy Systems, vol. 7, pp. 117-137, 2017. 
[10] C Wang, L Yin, L Zhang, D Xiang and R Gao "Metal oxide gas sensors: a review," Sensors, vol. 10, pp. 2088-2106, 2010.

[11] K Wetchakun, T Samerjai, N Tamaekong, C Liewhiran, C Siriwong, V Kruefu, A Wisitsoraat, A Tuantranont and S Phanichphant, "Semiconducting metal oxides as sensors for environmentally hazardous gases," Sensors and Actuators B: Chemical, vol. 160, pp. 580-591, 2011.
[12] N Nagar and P I Yazid, "Perangkat lunak sistem akuisisi data menggunakan Delphi," J. Oto. Ktrl. Instr. (J. Auto. Ctrl. Instr.), vol. 4 (1), pp. 17-24, 2012. 